Research Journal of Applied Sciences 5 (6): 444-450, 2010

ISSN: $1815-932 \mathrm{X}$

(C) Medwell Journals, 2010

\title{
Modeling of the Precipitation Layer by the Method of Finite Elements During the Process of Gaseous Nitriding of Steel 16MnCr5
}

\author{
${ }^{1}$ Naim Syla, ${ }^{2}$ Shukri Klinaku and ${ }^{1}$ Fisnik Aliaj \\ ${ }^{1}$ Department of Physics, Faculty of Mathematical and Natural Sciences, \\ ${ }^{2}$ Faculty of Education, \\ University of Prishtina, Mother Theresa St. 5, 10000 Prishtina, Republic of Kosovo
}

\begin{abstract}
Gaseous nitriding process is a diffusion process. This kind of process is described by the differential equation known as the Fick's second law. Its solutions depend on the condition of integration and the geometry of the problem. For the irregular geometry and complicated conditions, analytical solutions are impossible. In these cases, researchers seek for a solution by approximate numerical methods. One of the wellknown methods is the Method of Finite Elements (MFE) and the support software for this method, utilized in this research is the ANSYS program. In the precipitation layer due to the creation of nitrides the strength of the material will increase. In this research, the increase of the strength is experimentally determined and the modeling of Orowan's stresses is carried out by MFE. In the next step, the obtained curves are compared and as a conclusion researchers see that the theory and the experiment are in agreement.
\end{abstract}

Key words: Nitriding, strengthening, Orowan's mechanism, modeling, analytical situation, precipitation

\section{INTRODUCTION}

If the surface of iron is enriched with nitrogen then its properties are improved. This phenomenon was known even in the 5-1 centuries B.C. In modern times as the first contribution accounts the A. Fry's publication in 1923 Nitrogen in iron, steel and particular steels-a new process of the surface tempering (Steel and Iron 40-1923). With the notion Nitriding we mean the process of thermo-chemical processing where the surface of the material is enriched with nitrogen-DIN 17014.

Which phases appear in this case on the surface of the material, depends on the temperature during the process and on the activity of nitrogen. A right answer on this problem researchers find in the Lehrer's diagram (Fig. 1) which shows the state of equilibrium between the atmosphere of the ammonia and the phases on the surface.

From the diagram of state (Fig. 1) can identify two cases. In the first case, for low activity of nitrogen and/or low temperature, nitrogen penetrates the crystalline lattice of iron and with existing alloy elements creates precipitation of tiny nitrides. Thus, on the surface of steel the so-called precipitation layer is created which is characterized by the profile of the concentration of nitrogen depending on the depth.

This process is known as the internal nitriding. In the second case, for high activity of nitrogen and/or high

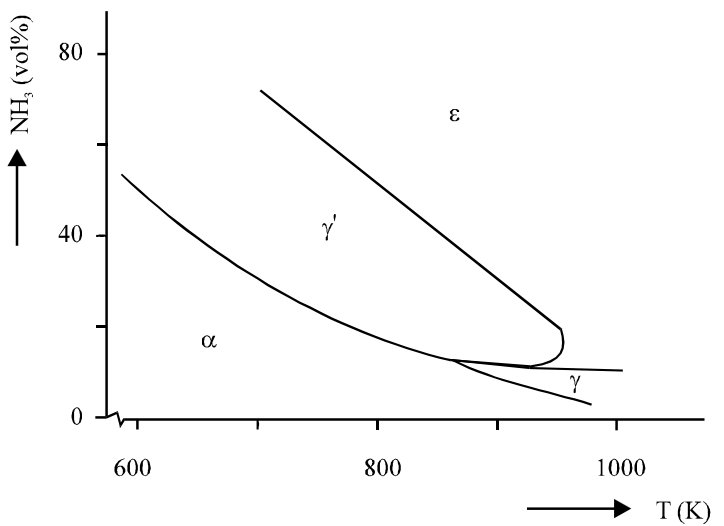

Fig. 1: Lehrer's diagram

temperature, nitrides of iron are created in which case above the precipitation layer the so-called compound layer is created and the process is known as external nitriding.

Compound layer: This layer is created in the beginning of the nitration (Fig. 2). It consists of nitrides $\varepsilon$ and $\gamma^{\prime}$. Compound layer has a high hardness and improves the properties of the material against consumption. The thickness of the layer is increased in time and with an increase of temperature of nitriding whereas the chemical composition is determined by the offer with

Corresponding Author: Naim Syla, Department of Physics, Faculty of Mathematical and Natural Sciences,

University of Prishtina, Mother Theresa St. 5, 10000 Prishtina, Republic of Kosovo 


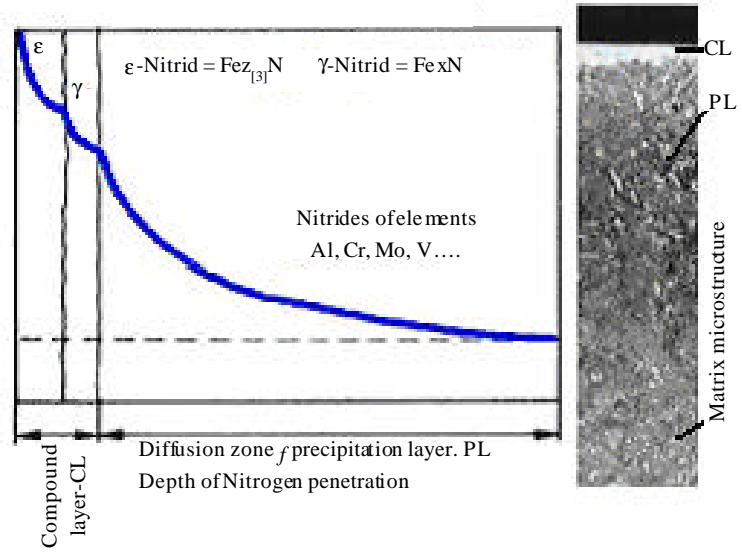

Fig. 2: Nitriding layer

nitrogen. After the ground etching, this layer is clearly discernible, thin and in the beginning of the layer.

Precipitation layer: The structure of this layer Fig. 2 depends on the matrix of the material as well as on the duration and the temperature of nitriding. The higher the presence of the alloy elements, the higher is the strength of the layer in the periphery whereas the depth of the nitriding layer will decrease. After the ground etching this layer is also clearly discernible and as a result of submicroscopic precipitations has a dark color. Precipitation layer is also hard and plays the role of a supportive sublayer for the compound layer. Submicroscopic precipitations of the nitrides represent a basis for the strengthening in the nitriding layer.

\section{STRENGTHENING}

Strength of the nitriding layer is determined by the Vickers' method with small load of HV0. 1. Curves of strength are taken with automatic microstrengthmeter PCE from LECO Company. Pressure with load is carried out in two parallel series.

Then the measurement of the strength is carried out also for five spots in the matrix zone i.e., in the nonnitriding zone. Characteristic quantities determined in this case are strength of the $\mathrm{RH}$ periphery, strength of the $\mathrm{KH}$ matrix and the strengthening $\Delta \mathrm{H}=\mathrm{RH}-\mathrm{KH}$. Maximum strengthening is normalized to 1 i.e., for each value of strengthening find (Fig. 3):

$$
\Delta \mathrm{H}^{\prime}=\Delta \mathrm{H} / \Delta \mathrm{H}_{\max }
$$

Precipitation tempering (Orowan's mechanism): In alloys reactions can take place that lead to the creation of precipitations which are different from the matrix due to both composition and the level of regularity and represent a different phase.
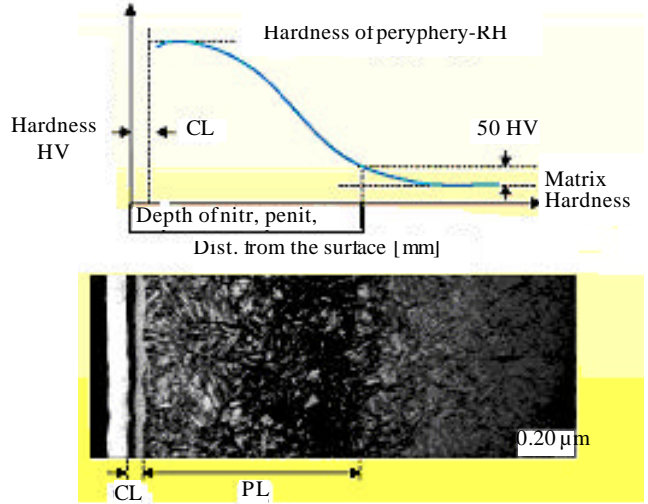

Fig. 3: Determination of the depth of nitrogen penetration with the help of the strength curve according to DIN 50190 part 3

Precipitations cause activities that prevent the movement of dislocations. Important parameters in this process are hardness of precipitations, volume part and the distance between precipitations as well as the shape and their distribution. According to Gottstein incoherent phase boundaries and the intergranular boundaries are untenable obstacles for dislocations. Nevertheless, dislocations can avoid precipitations through the Orowan's mechanism. During their movement dislocations cannot be intercepted by the precipitations but they instead circulate around each other many times (Fig. 4). For the value:

$$
\sigma=\mathrm{G} \cdot \mathrm{b} /(1-2 \mathrm{r})
$$

A critical state will occur where:

$2 \mathrm{r}=$ The diameter of precipitation

$1=$ The average distance from the center of a precipitation to the center of another precipitation 

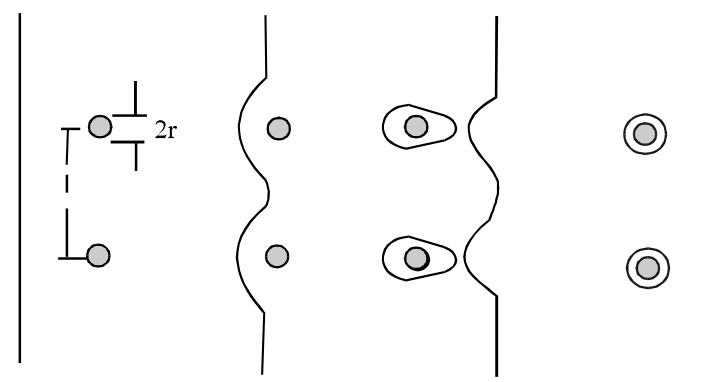

Fig. 4: Different positions of the Orowan's machanism for avioding precipitations. One circle of dislocations remains at the precipitations

$1-2 r=$ The free length of dislocations

$\mathrm{G}=$ The sheer module

$\mathrm{b}=$ The Burges' vector

During the further movement of dislocations, the radius of curvature will increase again and as a result we will not have a further increase of stress. Finally, antiparallel dislocations after the precipitations will meet and as a result a state without dislocations will be created. Nevertheless, at the particle will remain the so-called stress ring.

This mechanism of circulation of precipitations is known as the Orowan's mechanism. According to the rule: if precipitations are small in comparison with the distance between them $(1>>2 r)$ will have Orowan's stresses. For the ferrite steels, according to Gawne and Lewis (1985), Orowan's stresses are calculated by the expression:

$$
\sigma=\left(8,9 \cdot f^{1 / 2} / \mathrm{x}\right) . \text { In. }(1630 \cdot \mathrm{x})
$$

where, $\mathrm{f}$ and $\mathrm{x}[\mu \mathrm{m}]$ represent the volume part and the diameter of precipitations, respectively. If precipitations have a spherical form then take:

$$
\mathrm{f}=\mathrm{N} \cdot \mathrm{v}
$$

Where: $\mathrm{N}$ is the number of precipitations and $\mathrm{v}=4 / 3 \pi \cdot \mathrm{r}^{3}$ is the volume of a single precipitation Substitute $\mathrm{x}=2 \mathrm{r}$ and obtain $\mathrm{v}=\pi / 6 \mathrm{x}^{3}$ whereas the Eq. 2 takes the form:

$$
\begin{gathered}
f=N . v=N \frac{\pi}{6} x^{3} \\
x=\left(\frac{6}{\pi} \cdot \frac{f}{N}\right)^{1 / 3} .10^{6}[\mu \mathrm{m}]
\end{gathered}
$$

Finally for the Orowan's stresses researchers have:

$$
\sigma=\frac{8,9 \cdot f^{1 / 2}}{\left(\frac{6}{\pi} \cdot \frac{\mathrm{f}}{\mathrm{N}}\right)^{1 / 3} \cdot 10^{6}} \cdot \operatorname{In} \cdot\left[1630\left(\frac{6}{\pi} \cdot \frac{\mathrm{f}}{\mathrm{N}}\right)^{1 / 3} \cdot 10^{6}\right]
$$

\section{MODELING}

\section{Quantitative model for the kinetics of the increase of the nitriding layer}

Creation of the embryo of the precipitations: Driving force of every phase transformation is the difference of the free enthalpy $\Delta \mathrm{G}_{\mathrm{v}}$ between the initial phase and final phase. As the process of phase transformations begins, atoms of the initial phase will be repositioned through diffusion. As a result of this process, a new phase is created that has a lower free enthalpy. The new phase is separated from the initial phase through the surface boundary. For the creation of this boundary, certain energy, the so-called energy of the surface boundary is needed. Furthermore in most cases the energy of deformation must be taken into account because the process of phase transformation is closely related to volume changes. The total difference of the free energy for an embryo with a spherical form with a radius $r$ and a crystal is:

$$
\mathrm{G}=\Delta \mathrm{G}^{\mathrm{v}}+\Delta \mathrm{G}^{s}
$$

Where:

$$
\Delta \mathrm{G}^{\mathrm{v}}=\Delta \mathrm{G}_{\mathrm{v}} \cdot \frac{4}{3} \pi \cdot \mathrm{r}^{3}, \Delta \mathrm{G}^{s}=\gamma \pi \cdot \mathrm{r}^{2}
$$

That is:

$$
\begin{aligned}
& \mathrm{G}=\Delta \mathrm{G}_{\mathrm{v}} \cdot \frac{4}{3} \pi \cdot \mathrm{r}^{3}+\gamma \pi \cdot \mathrm{r}^{2} \\
& \frac{\mathrm{dG}}{\mathrm{dr}^{\mathrm{r}=\mathrm{r}^{*}}}=0 \Rightarrow \mathrm{r}^{*}=-\frac{2 \gamma}{\Delta \mathrm{G}_{\mathrm{v}}}
\end{aligned}
$$

where, $\mathrm{r}^{*}$ is the critical radius of the embryo. The total energy for $r=r^{*}$ is:

$$
\mathrm{G}^{*}=\frac{16 \pi \gamma^{3}}{3 \Delta \mathrm{G}_{\mathrm{v}}^{2}}
$$

where, $\gamma=0.2 \mathrm{Jm}^{2}$ is the surface energy (Robson et al., 1997) and according to Cahn et al. (1995), $\Delta \mathrm{G}_{\mathrm{v}}$ is:

$$
\Delta \mathrm{G}_{\mathrm{v}}=\mathrm{V}_{\mathrm{m}} \mathrm{R} \cdot \mathrm{T}\left(\mathrm{C}_{\mathrm{Cr}}^{\mathrm{CrN}} \operatorname{In} \frac{\mathrm{C}_{\alpha}^{\mathrm{Cr}}}{\mathrm{C}_{\alpha}^{\mathrm{Cr}, 0}}+\mathrm{C}_{\mathrm{N}}^{\mathrm{CrN}} \operatorname{In} \frac{\mathrm{C}_{\alpha}^{\mathrm{N}}}{\mathrm{C}_{\alpha}^{\mathrm{N}, 0}}\right)
$$

$\mathrm{C}_{\mathrm{Cr}}{ }_{\mathrm{CrN}}, \mathrm{C}_{\mathrm{N}}^{\mathrm{CrN}}$ are the concentrations of chrome and nitrogen in $\mathrm{CrN}$, respectively. These concentrations are calculated as follows:

$$
\begin{aligned}
\mathrm{CrN}= & \mathrm{m}_{\mathrm{Cr}}+\mathrm{m}_{\mathrm{N}}=51.996+14.007=66.003 \\
& 66.003 / 51.996=78.8 \mathrm{Ma} \% \mathrm{Cr} \\
& 66.003 / 14.007=21.2 \mathrm{Ma} \% \mathrm{~N}
\end{aligned}
$$

That is:

$$
\mathrm{C}_{\mathrm{Cr}}^{\mathrm{CrN}}=0.788, \mathrm{C}_{\mathrm{N}}^{\mathrm{CrN}}=0.212
$$


where, $\mathrm{C}_{\alpha}^{\mathrm{Cr}, \mathrm{O}}, \mathrm{C}_{\alpha}^{\mathrm{N}, 0}$ are the minimal concentrations of chrome and nitrogen in $\alpha$-Ferrit which are calculated from the product of solubility (Kunze, 1990);

$$
\log [\% \mathrm{Cr}][\% \mathrm{~N}]=-2686 / \mathrm{T}+0.39
$$

Classical theory of Johnson-Mehl-Avram for precipitations: If the fact that the particles of precipitations are increased in an isotropic way and that their shape is spherical is taken into account then for their radius we have:

$$
\mathrm{r}=\chi(\mathrm{t}-\tau)^{1 / 2}
$$

Where:

$\chi=$ Three-dimensional constant of the quantity

$\tau=$ The incubation time during which particles of precipitations take the effective shape

For the system $\mathrm{Cr}-\mathrm{Fe}$ this constant is calculated by the expression(Robson et al., 1997):

$$
\chi \cong \frac{\left(\overline{\mathrm{C}_{\mathrm{Cr}}}-\mathrm{C}_{\mathrm{Cr}}^{0}\right)^{1 / 2}}{\left(\mathrm{C}_{\mathrm{Cr}}^{\mathrm{Cr}}-\mathrm{C}_{\mathrm{Cr}}^{0}\right)^{1 / 2}} \cdot \mathrm{D}_{\mathrm{Cr}}^{1 / 2} \cdot \sqrt{2}
$$

where, $\overline{\mathrm{C}_{\mathrm{Cr}}}$ is that part of concentration of chrome in steel that contributes in creation of the nitride of $\mathrm{CrN}$ type. Based on investigations carried out by electronic microscope, it is proved that about $1 / 3$ of the concentration of chrome contributes in creation of the nitrides of $\mathrm{CrN}$ type. This type of nitrides is responsible for the strengthening:

$$
\mathrm{D}_{\mathrm{Cr}}=1 \cdot 5 \cdot 10^{-4} \exp \left(\frac{-240000}{\mathrm{RT}}\right) \mathrm{m}^{2} \mathrm{~s}^{-1}
$$

It is the diffusion coefficient of chrome in ferrit (Robson et al., 1997). Volume of a single particle for the time interval $\mathrm{t}-\tau$ is:

$$
\mathrm{V}=\left(\frac{4}{3}\right) \cdot \pi \cdot x^{3} \cdot(\mathrm{t}-\tau)^{3 / 2}
$$

If it is assumed that for the time interval $\Delta$ t have small increases of volume then this increase for the initial (first) interval is:

$$
\Delta \mathrm{V}_{1}^{\mathrm{e}}=\left(\mathrm{I}_{1} \cdot \mathrm{V} \cdot \mathrm{t}_{1}\right) \cdot\left(\mathrm{C} \cdot \chi_{1}^{3} \cdot \mathrm{t}_{1}^{3 / 2}\right)
$$

Where:

$$
\mathrm{C}=\frac{4 \pi}{3}
$$

Whereas, I the nucleation rate per unit volume and according to the classical theory this is equal to:

$$
I=N \frac{k T}{h} \exp \left[\frac{-\left(G^{*}+Q^{*}\right)}{k T}\right]
$$

Where:

$\mathrm{N}=$ The number of nucleation sites per unit volume

$Q^{*}=$ The activation energy of volume diffusion

$\mathrm{G}^{*}=$ The free energy needed for passing through the potential barrier

This energy is equal to:

$$
\mathrm{G}^{*}=\frac{16 \pi \eta^{3} \gamma^{3}}{3 \Delta \mathrm{G}_{\mathrm{v}}^{2}}
$$

Where:

$\gamma \quad=$ The energy per unit of area

$\eta=\mathrm{A}$ factor that depends on the geometry and for cases when embryos have a spherical shape is taken equal to 1

$\Delta \mathrm{G}_{\mathrm{v}}=$ The chemical driving force for embryos per unit of volume

Volume increase for the second time interval is:

$$
\begin{aligned}
& \Delta \mathrm{V}_{2}^{\mathrm{e}}=\left(\mathrm{I}_{2} \cdot \mathrm{V} \cdot \Delta \mathrm{t}_{2}\right) \cdot\left(\mathrm{C} \cdot \chi_{2}^{3} \cdot \Delta \mathrm{t}_{2}^{3 / 2}\right)+ \\
& \frac{3}{2} \mathrm{I}_{1} \cdot \mathrm{V} \cdot \Delta \mathrm{t}_{1} \cdot \mathrm{C} \cdot \chi_{2}^{3} \cdot\left(\Delta \mathrm{t}_{1}+\Delta \mathrm{t}_{2}\right)^{1 / 2} \Delta \mathrm{t}_{2}
\end{aligned}
$$

The second term is the contribution in growth of than particles from the first time interval. If the time interval is constant then it can take:

$$
\Delta \mathrm{V}_{2}^{\mathrm{e}}=\mathrm{C} \cdot \mathrm{V} \cdot \Delta \mathrm{t}^{5 / 2} \cdot \chi_{2}^{3}\left(\mathrm{I}_{2}+\frac{3}{2} \sqrt{2} \cdot \mathrm{I}_{2}\right)
$$

Or in general, after $m$ time intervals that will have a volume increase:

$$
\Delta \mathrm{V}_{\mathrm{m}}^{\mathrm{e}}=\mathrm{C} \cdot \mathrm{V} \cdot \Delta \mathrm{t}^{5 / 2} \cdot \chi_{\mathrm{m}}^{3} \cdot\left(\mathrm{I}_{\mathrm{m}}+\frac{3}{2} \sqrt{2} \cdot \mathrm{I}_{\mathrm{m}-1}+\ldots . .+\frac{3}{2} \sqrt{\mathrm{m}} \cdot \mathrm{I}_{1}\right)
$$

Method of Finite Elements (MFE)-temperature field: Method of Finite Elements (MFE) is a method for solving different problems in the field of mathematical physics. By a corresponding differential equation can describe the behavior of the structure influenced by the external or internal quantities (for example: temperature, mechanical force, electric field, magnetic field, diffusion, etc.). Since, the analytical solution of some differential equations is possible only for simple geometries and conditions, usually approximate numerical methods are used for solving differential equations. One of these methods is the method of finite elements and its support software is the ANSYS program.

According to the classical method the function increment is stretched over the entire integration area (entire structure) whereas according to MFE function is taken so that it is stretched only over particular areas of integration. Function must be of such a kind that ensures 
the transition condition (during the transition from one part of the zone to the neighboring part of the zone, the function is continuous). On the other hand, the approximate function for the entire area of integration is built from the all solutions of the parts. According to the MFE method start from an integral form. This means that the integral expression is minimized. Usually, the principle of minimum of potential energy is used. Potential energy $\pi$ of the entire structure is equal to the sum of contributions of particular elements $\pi_{e}$. If the approximate function is entered into the expression for the energy $\pi$ then the potential energy is a function of unknown degrees of freedom, for instance, node temperatures $\{\mathrm{T}\}$, i.e., $\pi=\pi\{\mathrm{T}\}$. Vector $\{\mathrm{T}\}$ shows the temperature of all nodes. From the condition of extremum:

$$
\frac{\partial \pi\{\mathrm{T}\}}{\partial\{\mathrm{T}\}}=0
$$

There is find that the set of equations for evaluation of unknown temperatures for each node. In matrix form this set of equations can be written in the form:

Where:

$$
[\mathrm{k}] \cdot\{\mathrm{T}\}=-\{\mathrm{Q}\}
$$

$[\mathrm{k}]=$ The matrix of conductivity of the order $(n, n)$ where $\mathrm{n}$ is the number of nodes

$\{\mathrm{T}\}=$ The vector of the node temperatures

$\{\mathrm{Q}\}=$ The vector of operating quantity Node temperature

$\{\mathrm{T}\}=$ Found from the solution of the set of equations

$$
\{\mathrm{T}\}=-[\mathrm{k}]^{-1} \cdot\{\mathrm{Q}\}
$$

Before we discuss theoretical basis of this method, it will explain why use this method in temperature field. ANSYS program doesn't recognize many variables

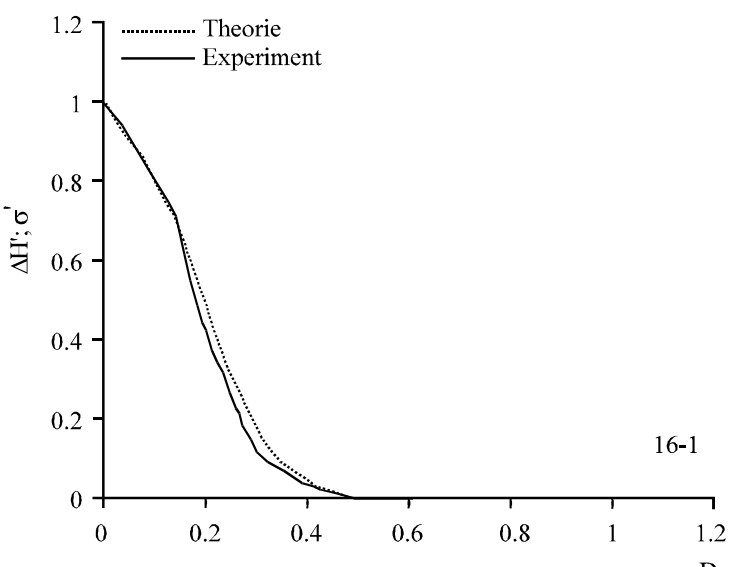

Depth (mm) (parameters in ANSYS). Mainly it recognizes parameters from the mechanics, temperature and fluids. Differential equations can be specified also for different problems of electrostatics, diffusion, magnetics etc. For example, ANSYS doesn't recognize the parameter that represents the coefficient of diffusion but it recognizes parameters $\mathrm{T}$ and $\mathrm{k}$. In the case, $\mathrm{T}$ represents the concentration of diffuse particles and $\mathrm{k}$ represents the parameter of the coefficient of diffusion. This becomes possible since differential equations are similar in form.

\section{RESULTS}

In the following we will represent the experimental and theoretical results for steel $16 \mathrm{MnCr} 5$. For this steel, the process of gas-nitriding is carried out in different temperatures and times. In Table 1 and 2 concentrations

\begin{tabular}{lc} 
Table 1: Concentration of alloy elements for steel 16MnCr5 \\
\hline Elements & Concentration \\
\hline C & 0.180 \\
Cr & 0.710 \\
Mn & 1.060 \\
V & 0.001 \\
Mo & 0.009 \\
Si & 0.310 \\
S & 0.026 \\
P & 0.028 \\
Al & 0.088 \\
\hline
\end{tabular}

Table 2: Conditions for nitriding and sample labelling

\begin{tabular}{lrr}
\hline Parameters & Time (h) & Sample label \\
\hline Temperature $\left(\mathbf{5 1 0 ^ { \circ }} \mathbf{C}\right)$ & 16 & $16-1$ \\
& 36 & $16-3$ \\
& 64 & $16-5$ \\
& 100 & $16-7$ \\
Temperature $\left(\mathbf{5 5 0} 0^{\circ} \mathrm{C}\right)$ & & \\
& 9 & $16-9$ \\
& 16 & $16-11$ \\
& 36 & $16-13$ \\
& 64 & $16-15$ \\
\hline
\end{tabular}

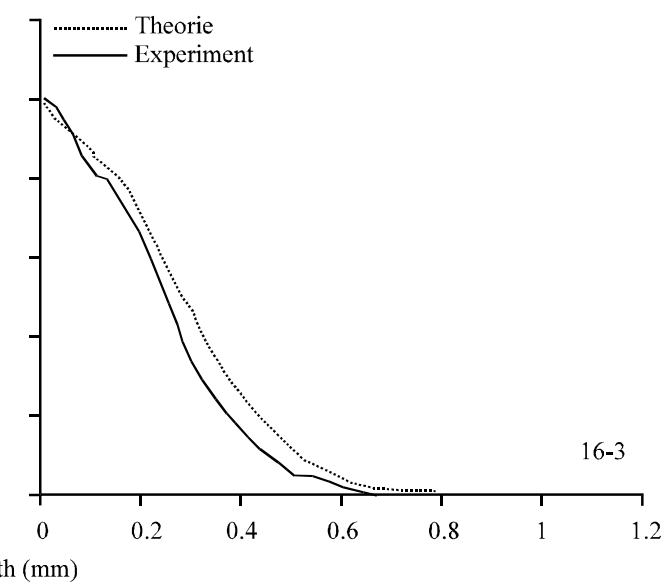

Fig. 5: Continue 
Res. J. Applied Sci., 5 (6): 444-450, 2010
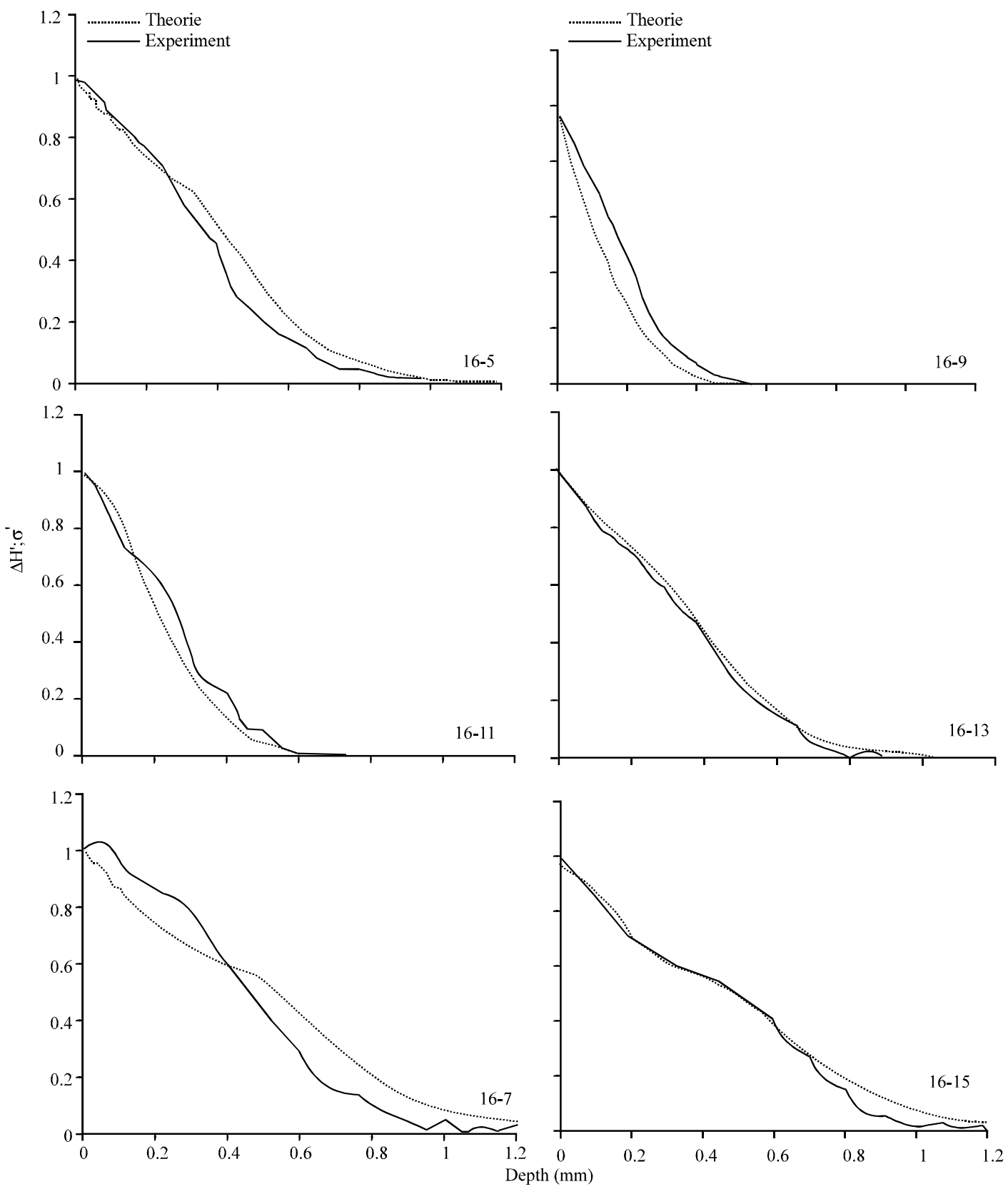

Fig. 5: Comparison of exerimental and theoretical results for steel $16 \mathrm{MnCr} 5$ after the process of gas-nitriding, as a function of the parameters of nitriding-time and temperature

of alloy elements of steel and conditions of gasnitriding are shown. As an experimental result is strengthening i.e., its normalized value to 1 whereas as a theoretical result is the Orowan's stress i.e., its normalized value to 1 as well. In Fig. 5 the results for the shown steel as a function of parameters of gas-nitriding are shown

\section{CONCLUSION}

In spite of approximations (shape of spherical particles, approximate value of concentration of chrome in steel, effects of decarbonization, porosity etc., not taken into account) from Fig. 5, it is clearly seen that the curves are not very different form each other. Modeling with the 
method of finite elements and simulation in ANSYS of the processes that are described by differential equations of the type of second Fick's law, depends on the condition of solution and the geometry of the problem. For complicated conditions and geometries, the program must be written in the language of parameters that ANSYSAPDL recognizes. Certainly, the precipitation layer can be modeled by the method of finite elements and the problem can be also simulated in ANSYS.

\section{ACKNOWLEDGEMENTS}

This research is a result of the co-operation between University of Prishtina and TU-BA Freiberg and was financially supported by DAAD (German Academic Exchange Program). The experimental research was performed in the Institute for Materials Science, FreibergGermany. The researchers would like to express the highest gratitude to DAAD and to the personnel of the Institute for their help and support.

\section{REFERENCES}

Cahn, R.W., P. Haasen and E.J. Kramer, 1995. Materias Science and Technology: A Comprehensive Treatment. Vol. 5, Wiley-VCH, Weinheim.

Clemens Groth and Günter Müller, 2001. FEM für Praktiker-Band 3: Temperaturfelder, expert verlag GmbH, Renningen.
Clemens Groth and Günter Müller, 2002. FEM für Praktiker-Band 1: Grundlagen, expert verlag $\mathrm{GmbH}$, Renningen.

Gawne, D.T. and G.M.H. Lewis, 1985. Strengthening mechanisms in high-strength microalloyed steels. Mater. Sci. Technol., 1: 183-191.

Gottstein Günter, 1998. Physikalische Grundlagen der Materialkunde. Springer, Aachen.

Kunze, J., 1990. Nintrogen and Carbon in Iron and Steel Thermodynamics. Akadmie Velag, Berlin, Germany.

Peter Haasen 1985. Physikalische Metallkunde. Akadmie Verlag, Berlin.

Robson, J.D. and H.K.D.H. Bhadeshia, 1997. Modelling precipitation sequences in power plant steels Part 1Kinetic theory. Mater. Sci. Technol., 13: 631-639.

Ruth Chatterjee-Fischer and Mitautoren, 1995. Wärmebehandlung von Eisenwerkstoffen, Berlin.

Schacherl, R.E. and E.J. Mittemeijer, 2004. Nitrieren von Fe-Cr-Legierungen. HTM 59 (2004) 5, Carl Hanser Verlag, München, pp: 312-319.

Spies, H.J. and D. Bergner, 1998. Innere Nitrierung von Eisenwerkstoffen. HTM 47 (1998) 6, Carl Hanser Verlag, München, pp: 346-355.

Spies, H.J., H.J. Berg und H. Zimdars, 2003. Fortschritte beim sensorkontrollierten Gasnitrieren and nitrocarburieren. HTM 58 (2003) Carl Hanser Verlag, München, pp: 189-197. 